\title{
Systemic iron homeostasis in female athletes: hepcidin, exercise and sex influence
}

\author{
Laura Barba-Moreno, Víctor M. Alfaro-Magallanes, Francisco Javier Calderón, Ana B. Peinado \\ LFE Research Group, Department of Health and Human Performance, Universidad Politécnica de Madrid, Madrid, Spain.
}

doi: 10.18176/archmeddeporte.0009

Recibido: 30/10/2019

Aceptado: $07 / 07 / 2020$

Key words:

Iron deficieny. Oestrogen. Progesterone. Female athlete. Iron absorption.

\section{Summary}

Iron is necessary for adequate deliver oxygen to the tissues since it is an essential component of the haemoglobin. However, iron deficiency remains a common problem among athletes, particularly for women experiencing the menstrual bleeding every month. The iron losses through menstrual blood loss during the early follicular phase (or menses) and an inadequate dietary intake of iron are two important factors contributing to this disease. Furthermore, the large hormonal changes that women experience along the menstrual cycle, especially in oestrogen and progesterone may influence on the optimization of iron absorption. Iron absorption is mainly mediated by hepcidin hormone, which seems to be affected by several stimulus and factors such as oestrogen and progesterone concentrations. Moreover, the regular practice of exercise is another important modulator of this hormone. Therefore, premenopausal active females are the most susceptible population to develop an iron deficiency or iron deficiency anemia, affecting their health and performance due to the less iron availability within the body and consequently a reduction of haemoglobin which compromise the oxygen transport. To date, most studies have not explored the acute post-exercise hepcidin response taking endogenous and exogenous sexual hormones influence into account. This narrative review will focus on how iron homeostasis is modulated by different factors mainly influenced by exercise and female sexual hormones.
Palabras clave: Hierro. Estrógeno. Progesterona. Mujer atleta. Anemia.

\section{Homeostasis sistémica del hierro en mujeres deportistas: hepcidina, ejercicio y la influencia del sexo}

\begin{abstract}
Resumen
El hierro es necesario para suministrar adecuadamente el oxígeno a los tejidos, ya que es un componente esencial de la hemoglobina. Sin embargo, la deficiencia de hierro sigue siendo un problema común entre los atletas, particularmente para las mujeres que experimentan el sangrado menstrual cada mes. Las pérdidas de hierro producidas tras la el sangrado menstrual durante la fase folicular temprana (o menstruación), además de una ingesta dietética inadecuada de hierro son dos factores importantes que contribuyen a esta enfermedad. Además, los grandes cambios hormonales que experimentan las mujeres a lo largo del ciclo menstrual, especialmente en el estrógeno y la progesterona, pueden influir en la optimización de la absorción de hierro. La absorción de hierro está mediada principalmente por la hormona hepcidina, que parece verse afectada por varios estímulos y factores como las concentraciones de estrógeno y progesterona. Además, la práctica regular de ejercicio es otro importante modulador de esta hormona. Por lo tanto, las mujeres activas premenopáusicas son la población más susceptible de desarrollar una deficiencia de hierro o anemia ferropénica, lo que afecta a su salud y rendimiento debido a la menor disponibilidad de hierro en el cuerpo y en consecuencia, a la reducción de la hemoglobina que compromete el transporte de oxígeno. Hasta la fecha, la mayoría de los estudios no han explorado la respuesta aguda de la hepcidina después del ejercicio teniendo en cuenta la influencia de las hormonas sexuales endógenas y exógenas.

Esta revisión narrativa se centrará en cómo la homeostasis del hierro es modulada por diferentes factores influenciados principalmente por el ejercicio y las hormonas sexuales femeninas.
\end{abstract}




\section{Introduction}

Iron deficiency (ID) is the most common nutritional deficiency worldwide, affecting specially to premenopausal women, around $40 \%$ in the developing world due to the additional iron demands of menstruation and pregnancy'.

Athletes present a higher prevalence of ID than common population', particularly those involved in endurance sports ${ }^{2}$. In women, the regular exercise practice combined with menstrual blood losses, and in occasions accompanied by inadequate iron intake may compromise iron status ${ }^{3,4}$. Therefore, the prevention of ID, especially in females participating in endurance-type exercise are of major importance in order to avoid this event.

Additionally, oral contraceptive (OC) agents have been reported to improve iron parameters levels ${ }^{5-7}$, since lesser quantity and shorter duration of menstrual blood loss is reported in OC users ${ }^{7}$. However, OC comes in a variety of formulations that contain several concentrations of synthetic ethinyl estradiol and progesterone, and the potential side effects in the measurement variables may be different due to the differences in dosages.

Systemic iron homeostasis depends primarily on the hepcidin hormone, which is the master regulator of iron homeostasis. Hepcidin inhibit the cellular efflux of iron to plasma by binding to ferroportin and inducing its internalization and degradation, therefore this fact modulates duodenal iron absorption and recycling in macrophages ${ }^{8}$.

The regulation of hepcidin hormone occurs via many different stimuli including iron status, increments of interleukin-6 (IL-6), inflammation or hypoxia, among others, causing a future increase or decrease in iron absorption ${ }^{8}$. Furthermore, female sex hormones have been reported to exert a potential effect on hepcidin expression, specially oestrogen and progesterone $e^{9,10}$, which may consequently influence on iron absorption.

This narrative review aims to address the different stimuli and mechanisms regulating hepcidin hormone, considering exercise and female sex hormones influence and their corresponding consequences on iron homeostasis.

\section{Hepcidin-ferroportin system}

Hepcidin is synthesized and released mainly by the liver and it acts controlling the membrane expression of ferroportin ${ }^{11}$. Hepcidin binds to ferroportin and degrades it, so the hepcidin-ferroportin interaction controls the flux of iron into the plasma and consequently the iron used by tissues ${ }^{11}$. The liver becomes a sensor and an effector regarding the control of iron metabolism, recognizing different stimuli: intra and extracellular iron concentrations (hepatic and plasma iron), the erythropoietic needs and the increase in concentrations of inflammatory markers ${ }^{12}$.

Increased hepcidin expression in hepatocytes occurs when iron levels are abundant in the body, which reduce its absorption and release from stores (mainly ferritin within hepatocytes and macrophages). When iron is deficient, hepatocytes decrease hepcidin synthesis, inhibiting ferroportin degradation and allowing iron entrance into plasma ${ }^{13}$.
Aforementioned stimulus can be activated or supressed by different mechanisms. One of them is exercise, which has influence over several pathways regulating hepcidin production ${ }^{14-16}$. Nevertheless, this influence need more research to provide evidence, especially in female athletes, where exercising is combined with sex hormones variations along the menstrual cycle.

\section{Mechanisms regulating hepcidin- ferroportin system}

Several mechanisms regulate hepcidin-ferroportin axis in order to maintain iron homeostasis. These mechanisms are not isolated, as they interact and cooperate between them in order to adjust iron levels in vivo.

\section{Intra and extracellular iron homeostasis}

Basically, iron-dependent mechanisms in the body, mainly erythropoiesis, are addressed by a tight coordination between iron absorption from the diet by enterocytes, iron recycling by macrophages following degradation of senescent erythrocytes, and iron release to plasma from ferritin reserves ${ }^{17}$. Most of the iron in the body is found as part of the haemoglobin contained in erythrocytes ${ }^{11}$. Erythropoiesis occurs in the bone marrow to compensate the daily destruction of senescent erythrocytes (lifespan of $\sim 90$ days). From the aforementioned iron supply processes, erythrocytes recycling by macrophages account approximately for $90 \%$ of the iron requirements ${ }^{18}$. The other $10 \%-20 \%$ depends on the iron absorption from the small intestine according to the body's needs.

Furthermore, the excess of iron in relation to the requirements is stored in liver, spleen, bone marrow, duodenum, skeletal muscle and other anatomical zones by means of two extraordinary proteins: ferritin and hemosiderin ${ }^{17}$. Within normal limits, the transformation of ferritin to hemosiderin could be the best evolutionary step to reduce iron toxicity, due to the low iron elimination capacity of the human body ${ }^{19}$.

Hepatocytes have the largest capacity for iron storage and when iron absorption and recycling do not meet the body iron demands, these iron stores supply the necessary iron to plasma, addressing the needs ${ }^{19}$. To export iron from cells (duodenal enterocytes, iron-storing hepatocytes and iron-recycling macrophages) into plasma, ferroportin is required ${ }^{20}$.

The aforementioned mechanisms cooperate together over the control of plasma iron concentration. Once in the plasma, iron is oxidized to join transferrin protein (the main iron transporter in plasma) which is mainly destined to supply iron to the bone marrow ${ }^{20}$.

When all of the above results in an increase in plasma iron, there is a decrease in iron absorption mediated by increments in hepcidin levels and subsequent ferroportin degradation ${ }^{21}$.

\section{Interleukin-6}

IL-6 as Myokine: IL-6 is produced locally in working skeletal muscle and can account for the increase in plasma IL-6 during exercise ${ }^{22}$. The 
intensity and duration of the exercise are determinants in the IL-6 production ${ }^{23}$ as well as the low muscle glycogen contents. In addition, IL-6 levels depend on the amount of muscle mass involved during exercise ${ }^{24}$.

According to some authors, cytokines and other peptides that are produced and released by muscle fibres and exert effects on metabolism (paracrine or endocrine) should be classified as "myokines"22. Musclederived IL-6 is released into the circulation during exercise participating in the maintenance of the glucose homeostasis and exercise-induce lipolysis due to the effect exerted on the liver and adipose tissue, respectively ${ }^{25}$.

Several authors have demonstrated a clear disassociation between IL-6 and tumor necrosis factor alpha (TNF- $\alpha)^{26}$. These authors showed that although intramuscular IL- 6 gene expression and protein release was remarkable during continuous contractile activity, no response for TNF- $\alpha$ was evident, indicating that IL- 6 is not always related or released after an inflammation process.

IL-6 as Cytokine: Infection or tissue injury are related to the production of cytokines that are released at the site of inflammation. The local inflammatory response is accompanied by a systemic response known as the acute phase response, in which several hepatocyte derived acute phase proteins are produced (C-reactive protein, transferrin, alpha-2 macroglobulin $)^{27}$.

Strenuous exercise has been reported in several occasions to develop inflammation in the body due to elevations in plasma of TNF- $\alpha$ and IL-6, but only as a result of marathon running ${ }^{28,29}$. Concurrently, exercise seems to have strong anti-inflammatory effects ${ }^{26,30}$. During exercise, IL-6 is the first cytokine present in the circulation. High circulating levels of IL-6 are followed by an increase of the anti-inflammatory cytokines IL-1 ra and IL-10 and inhibit the production of the proinflammatory cytokine TNF- $\alpha$ as shown in vitro ${ }^{31}$ and animal studies ${ }^{32,33}$.

Furthermore, according to some authors ${ }^{34}$, IL-6 stimulates the production of C-reactive protein, which has an important function in the induction of anti-inflammatory cytokines in circulating monocytes and in the suppression of the synthesis of proinflammatory cytokines in tissue macrophages.

According to Pedersen and Hoffman-Goetz ${ }^{27}$, IL-6 should be classified as an "inflammation-responsive" cytokine, since IL-6 does not directly induce inflammation. Therefore, to confirm an inflammatory state, IL-6 should not be considered in isolation, but together with the expression of other pro-inflammatory cytokines such as TNF- $\alpha$.

\section{Exercise influence on mechanisms regulating hepcidin}

The aforementioned mechanisims are affected acutely or chronically by exercise. The following sections describe the interaction of exercise with each of them.

\section{Exercise and iron status}

Body iron status has been reported to influence the previously described response of hepcidin to exercise. Healthy individuals have shown a positive association between ferritin and hepcidin concentrations, being higher the hepcidin levels in those subjects with higher ferritin reserves ${ }^{35}$. Two studies have described that the higher the ferritin reserves before exercise, the higher the hepcidin levels 3 hours post-exercise in response to IL-6 increase just post-exercise ${ }^{36,37}$. Curiously, when ferritin reserves are insufficient (below 30 micrograms $/ \mathrm{ml}$ ), hepcidin does not seem to experiment a significant increase after exercise, instead of the IL-6 peak produced at Oh post-exercise36. This fact points out that the body iron stores could act as a defensive mechanism against the hepcidin increase induced by exercise. This mechanism would be focused on allowing the body to restore the iron reserves and supply enough iron to plasma in order to meet the requirements for iron-dependent processes.

In addition, exercise produces iron losses that could affect body iron stores by several mechanisms, such as haemolysis, gastrointestinal bleeding, haematuria and/or sweating ${ }^{38}$. Exercise produces haemolysis during exercise, consisting on the destruction of red blood cells. Curiously, running exercise shows the most severe haemolysis, since the foot strikes repeatedly occurring in this discipline produce the destruction of erythrocytes ${ }^{39}$. As a result of haemolysis, haemoglobin and iron are released into the plasma.

Gastrointestinal bleeding and iron losses via the urinary tract and sweating are less usual or not powerfull enough to produce significant iron losses. However, considered as a whole, they can substantially contribute to the daily iron losses and reduce the athlete's iron status.

\section{Exercise and interleukin-6}

Most studies have identified IL-6 as an important upstream mediator of hepcidin induction by post-exercise inflammation ${ }^{14,37,38,40}$, however this does not necessarily imply an inflammatory state, since IL-6 is produced during exercise in absence of inflammation.

Some studies have reported that hepcidin levels seem to peak between 3-6 h subsequent to the peak in IL-6 elevation after an exercise bout ${ }^{41,42}$.

Since endurance exercise is able to significantly increase IL-6 levels, several studies have already investigated this time-course after exercise. A research study ${ }^{43}$ investigated in women the effects of two treadmill runs ( 60 and $120 \mathrm{~min}$ ) at $65 \%$ of $\mathrm{VO}_{2}$ max, finding that both runs resulted in significant increases in hepcidin 3 hours after exercise and preceded by significant increases in IL-6 immediately post-exercise. Furthermore, the 120 min treadmill run produced a higher increase of IL-6 levels that the 60 min treadmill run and consequently a noticeably higher hepcidin production, indicating a concentration dependent response of hepcidin to IL-6.

Consequently, a significant decrease in serum iron was produced 9 hours post-exercise. Several studies have reported similar results s2,44-46. $^{4}$

Only a few studies examined IL- 6 and hepcidin response after exercise in female athletes, but none of these studies analysed these variables under the influence of sexual hormones ${ }^{16,43,47}$ (Figure 1).

\section{Special considerations for physically active women}

Iron deficiency, with and without anaemia, has been mainly demonstrated in premenopausal females at a greater prevalence than men, because of the additional Fe demands of menstruation and preg- 
Figure 1. Iron importance on oxygen metabolism and the different stimulus affecting hepcidin regulation under sexual hormones influence. Inadequate iron status may reduce haemoglobin, red blood cell production (erythropoiesis) and subsequent endurance performance. Endurance exercise is known to produce haemolysis and increase inflammatory markers as IL-6, as well as modify extra and intra cellular iron concentration. Both signals are positive regulators of hepcidin expression and may explain exercise-induced iron deficiency or anaemia in athletes. The menstrual bleeding experienced by women may have a significant impact on haemoglobin and consequently affect endurance performance. The oestrogen and progesterone variations found during a regular menstrual cycle and with $\mathrm{OC}$ may influence on hepcidin levels, and subsequently on iron absorption. Hepcidin regulates plasma iron concentrations by controlling ferroportin (fpn) concentrations on iron-exporting cells including duodenal enterocytes, recycling macrophages of the spleen and liver, and hepatocytes. The iron concentrations in plasma are mainly destined to the bone marrow in order to develop the erythropoiesis.

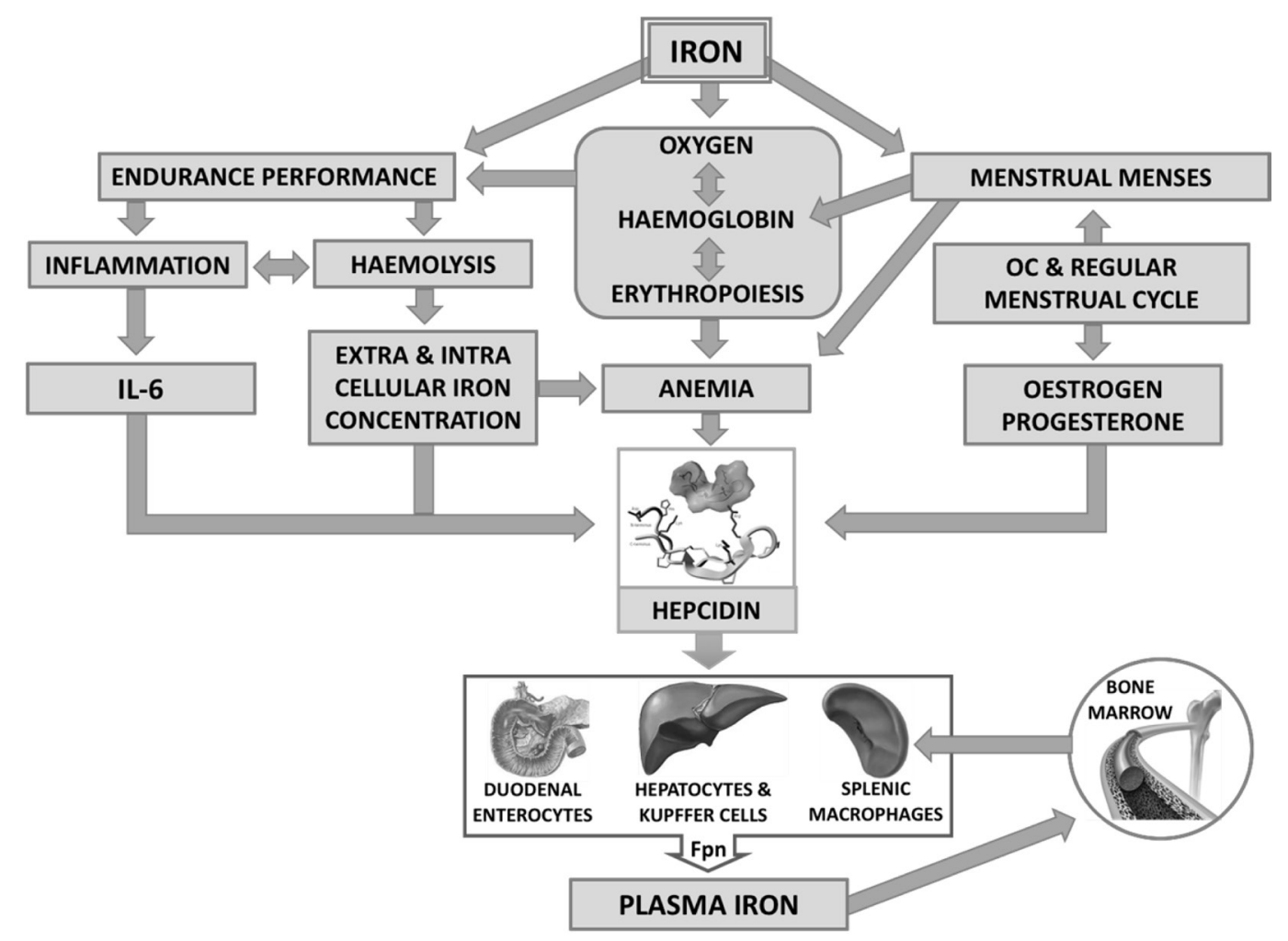

nancy ${ }^{48,49}$. Not only inadequate iron intake and losses of iron through menstruation could affect this population, but also regular exercise performance.

Menstrual blood loss may alter iron related parameters, as lower ferritin, haemoglobin or serum iron levels during menses ${ }^{50}$, and therefore to reduce physical performance. Consequently, the iron homeostasis in female athletes tends to be unbalanced due to menstrual losses, which are difficult to quantify.

These variations have been found in both women, eumenorrheic and those taking $\mathrm{OC}$, although fluctuations are much smaller in women under $\mathrm{OC}$ effects ${ }^{51}$.

Moreover, sex hormones like estradiol and progesterone have been related with iron metabolism parameters in the literature. These hormones may have an important role over IL-6 and hepcidin, regulating iron absorption ${ }^{52-54}$.

\section{Endogenous hormones influence on iron metabolism}

Oestrogen and progesterone may have an important effect over iron metabolism, modifying hepcidin and IL-6 activity. Despite one study reported that oestrogen was found to increase hepcidin gene expression $^{55}$, most studies have shown an inhibition of hepcidin expression by $17-\beta$ estradiol or oestrogen treatment $t^{55-58}$.

Some authors reported a downregulated hepcidin expression by estradiol in fish ${ }^{56}$. Hepcidin regulation in this study could have been mediated by IL-6, which has also been reported to be inhibited by oestrogen or 17- $\beta$ estradiol. However, IL-6 levels were not measured in these studies ${ }^{56}$. Shortly thereafter, a similar response in mice ${ }^{53,58}$, and in human liver cells was reported ${ }^{58}$. Similarly, a mouse model of oestrogen deficiency by ovariectomy was established, demonstrating that oestrogen is implicated in modulating iron homeostasis by governing hepatic hepcidin expression ${ }^{53}$. In the ovariectomized mice group, hepcidin 
expression was more elevated under oestrogen deficiency compared to the control group, following of a decrease in serum iron.

Other authors found that transcription of hepcidin was suppressed by estradiol treatment in human liver cells and that estradiol reduced hepcidin mRNA in wild-type mice ${ }^{58}$. These authors suggested that hepcidin inhibition by estradiol may increase iron uptake in order to compensate iron loss during menstruation, helping as well to increase iron stores in OC users.

A recent study of in vitro fertilization reported a reduction of serum hepcidin-25 by almost $40 \%$ when oestrogen stimulation occurred compared to the castration state ${ }^{57}$.

The results of these studies agree with an older study ${ }^{59}$, which demonstrated that serum hepcidin is higher in postmenopausal than premenopausal women. This novel mechanism by which estradiol could inhibit hepcidin levels, may help to increase iron absorption, iron release and recycling from storage cells ${ }^{58}$.

Furthermote, progesterone may up-regulate serum hepcidin in mice and humans. Progesterone concentrations were reported to increase hepcidin gene expression in zebrafish ${ }^{60}$. The same study investigated 20 women who were given progesterone as part of a standard in vitro fertilization protocol, reporting an increase in serum hepcidin levels after day 20 of a treatment with daily $50 \mathrm{mg}$ of intramuscular progesterone supplementation.

The suggested regulation of estradiol and progesterone over hepcidin may also occur via IL-6 as an intermediate step. Some authors, reported in premenopausal women higher IL-6 levels during the follicular phase when progesterone levels were low, and a significant reduction in IL-6 after ovulation when progesterone levels increased ${ }^{54}$. Contrary, other authors reported that IL-6 concentration were significantly higher in the luteal phase ${ }^{61}$.

Despite more scientific evidence is needed, as a result of these findings, it seems that sexual hormones may have potential effects on hepcidin and IL-6 regulation and consequently to impact iron homeostasis.

\section{Exogenous hormones influence on iron metabolism}

One of the most notable effect of $\mathrm{OC}$ would be the lesser quantity and shorter duration of menstrual blood loss ${ }^{7}$. This event may affect considerably to haemoglobin concentration and iron parameters. A previous study examined that menstrual blood loss decreased by approximately $50 \%$ in OC users $^{6}$. In addition, these findings could be related to the improve of iron parameters in the OC group, since ferritin levels were significantly enhanced in 10\%, regarding those women who did not use $\mathrm{OC}^{6}$. Previously to these findings, other studies reported in OC users significantly higher serum ferritin ${ }^{5,7}$, iron and total iron binding capacity ${ }^{7}$ in relation to nonusers.

Therefore, OC may improve iron stores by the reduction of menstrual blood loss or through the suppression of hepcidin via estradiol, and consequently optimizing exercise performance.

The steady loads of estradiol and progestin during the OC cycle have led a few authors to investigate the possible associations between exogenous sexual hormones and iron metabolism through hepcidin and IL-6 response. However, most of the studies reported that plasma IL-6 concentrations did not change between OC phases ${ }^{62,63}$.
Similarly, the first study investigating the post-exercise IL-6 and hepcidin response, reported similar results for serum IL-6 and hepcidin for both hormone-deplete and hormone-replete phases of a monophasic OC cycle $e^{64}$. These results indicated that exercise performed during the different phases of a monophasic OC cycle does not alter exercise induced IL-6 or hepcidin production and it may be linked to the lower dosage of estradiol delivered from the $\mathrm{OC}^{65}$.

\section{Conclusion}

Most studies presenting changes have been carried out in animals where estradiol or progesterone concentrations were infused with greater hormonal doses than those obtained from a normal menstrual cycle or with OC. Therefore, these findings cannot be applicable when premenopausal women are studied. Although literature is very reduced, for those females taking monophasic OC pills, hepcidin levels seem to be unaffected by exogenous hormones concentrations and therefore it seems it is not necessary to adjust the trainning session to the OC cycle. Regarding eumenorrheic women, more research studies are needed considering the effects of endogenous hormones concentrations on hepcidin production, since progesterone may have an opposite effect to oestrogen or even inhibiting oestrogens activity.

Hence, figure it out hepcidin behavior along menstrual cycle may provide information about when iron absorption could be more efficient. This might benefit those females suffering ID due to their demanding trainings and/or menstrual blood loss, resulting in a performance detriment or health impaired.

\section{Conflict of interest}

The authors declare no conflict of interest.

\section{Bibliography}

1. McClung JP. Iron status and the female athlete. J Trace Elem Med Biol. 2012;26:124-6.

2. Milic R, Martinovic J, Dopsaj M, Dopsaj V. Haematological and iron-related parameters in male and female athletes according to different metabolic energy demands. Eur J Appl Physiol. 2011;111:449-58.

3. Babic Z, Papa B, Sikirika-Bosnjakovic M, Prkacin I, Misigoj-Durakovic M, Katicic M. Occult gastrointestinal bleeding in rugby players. J Sports Med Phys Fitness. 2001;41:399-402.

4. DeRuisseau KC, Cheuvront SN, Haymes EM, Sharp RG. Sweat iron and zinc losses during prolonged exercise. Int J Sport Nutr Exerc Metab. 2002;12:428-37.

5. Milman N, Kirchhoff M, Jorgensen T. Iron status markers, serum ferritin and hemoglobin in 1359 Danish women in relation to menstruation, hormonal contraception, parity, and postmenopausal hormone treatment. Ann Hematol. 1992;65:96-102.

6. Larsson G, Milsom L, Lindstedt G, Rybo G. The influence of a low-dose combined oral contraceptive on menstrual blood loss and iron status. Contraception. 1992;46:327-34.

7. Frassinelli-Gunderson E, Margen S, Brown J. Iron stores in users of oral contraceptive agents. Am J Clin Nutr. 1985;41:703-12.

8. Ganz T. Hepcidin and iron regulation, 10 years later. Blood. 2011;117:4425-33.

9. LiX, Rhee DK, Malhotra R, Mayeur C, Hurst LA, Ager E, et al. Progesterone receptor membrane component-1 regulates hepcidin biosynthesis. J Clin Invest. 2016;126:389-401.

10. Lehtihet M, Bonde Y, Beckman L, Berinder K, Hoybye C, Rudling M, et al. Circulating hepcidin-25 is reduced by endogenous estrogen in humans. PLoS One. 2016;11:e0148802.

11. Ganz T, Nemeth E. Hepcidin and iron homeostasis. Biochim Biophys Acta. 2012;1823: 1434-43.

12. Ganz T. Systemic Iron Homeostasis. Physiol Rev. 2013;93:1721-41.

13. Ganz T. Macrophages and systemic iron homeostasis. J Innate Immun. 2012;4:446-53. 
14. Peeling P, Dawson B, Goodman C, Landers G, Wiegerinck ET, Swinkels DW, et al. Training surface and intensity: Inflammation, hemolysis, and hepcidin expression. Med Sci Sports Exerc. 2009;41:1138-45.

15. Sim M, Dawson B, Landers G, Swinkels DW, Tjalsma H, Yeap BB, et al. Oral contraception does not alter typical post-exercise interleukin-6 and hepcidin levels in females. J Sci Med Sport. 2015;18:8-12.

16. Roecker L, Meier-Buttermilch R, Brechtel L, Nemeth E, Ganz T. Iron-regulatory protein hepcidin is increased in female athletes after a marathon. Eur J Appl Physiol. 2005; 95:569-71.

17. Beaumont C, Delaby C. Recycling iron in normal and pathological states. Semin Hematol. 2009;46:328-38.

18. Drakesmith H, Nemeth E, GanzT. Ironing out Ferroportin. Cell Metab. 2015; 22:777-87.

19. Takami T, Sakaida I. Iron regulation by hepatocytes and free radicals. J Clin Biochem Nutr. 2011;48:103-6.

20. Zhang DL, Ghosh MC, Rouault TA. The physiological functions of iron regulatory proteins in iron homeostasis - an update. Front Pharmacol. 2014;5:1-12.

21. Nemeth E, Tuttle MS, Powelson J, Vaughn MB, Donovan A, Ward DM, et al. Hepcidin regulates cellular iron efflux by binding to ferroportin and inducing its internalization. Science. 2004;306:2090-3.

22. Pedersen BK, Akerström TCA, Nielsen AR, Fischer CP. Role of myokines in exercise and metabolism. J Appl Physiol. 2007;103:1093-8.

23. Ostrowski K, Asp S. Chemokines are elevated in plasma after strenuous exercise in humans. European journal of applied physiology. 2001;84:244-5.

24. Helge JW, Klein DK, Andersen TM, van Hall G, Calbet J, Boushel R, et al. Interleukin-6 release is higher across arm than leg muscles during whole-body exercise. Exp Physiol. 2011;96:590-8.

25. Pedersen BK. Muscle as a secretory organ. Compr Physiol. 2013;3:1337-62.

26. Steensberg A, Keller C, Starkie RL, Osada T, Febbraio MA, Pedersen BK. IL-6 and TNF-a expression in, and release from, contracting human skeletal muscle. Am J Physiol Metab. 2002;283:E1272-8.

27. Pedersen BK, Hoffman-goetz L. Exercise and the immune system: regulation, integration, and adaptation. Physiol Rev. 2000;80:1055-81.

28. Ostrowski K, Rohde T, Asp S, Schjerling P, Pedersen BK. Pro- and anti-inflammatory cytokine balance in strenuous exercise in humans. J Physiol. 1999;515:287-91.

29. Ostrowski K, Rohde T, Zacho M, Asp S, Pedersen BK. Evidence that interleukin-6 is produced in human skeletal muscle during prolonged running. J Physiol. 1998;508:949-53.

30. Petersen A, Pedersen B. The anti-inflammatory effect of exercise. J Appl Physiol. 2005; 98:1154-62.

31. Fiers W. Tumor necrosis factor Characterization at the molecular, cellular and in vivo level. FEBS Lett. 1991;285:199-212.

32. Mizuhara BH, Neill EO, Ogawa T, Kusunoki C, Otsuka K, Satoh S, et al. T cell activationassociated hepatic injury: mediation by tumor necrosis factors and protection by interleukin 6. Journal of Experimental Medicine. 1994;179:1529-37.

33. Matthys $P$, Mitera T, Heremans $H$, Van Damme J, Billiau A. Anti-gamma interferon and anti-interleukin-6 antibodies affect staphylococcal enterotoxin B-induced weight loss, hypoglycemia, and cytokine release in D-galactosamine-sensitized and unsensitized mice. Infect Immun. 1995;63:1158-64.

34. Pue C, Mortensen R, Marsh C, Pope, HA, Wewers M. Acute phase levels of C-reactive protein enhance IL-1 beta and IL-1ra production by human blood monocytes but inhibit IL-1 beta and IL-1ra production by alveolar macrophages. J Immunol. 1996; 156:1594-600.

35. Ganz T, Olbina G, Girelli D, Nemeth E, Westerman M. Immunoassay for human serum hepcidin. Blood. 2008;112:4292-7.

36. Peeling P, Sim M, Badenhorst CE, Dawson B, Govus AD, Abbiss CR, et al. Iron status and the acute post-exercise hepcidin response in athletes. PLoS One. 2014;9:e93002.

37. Peeling P, McKay AKA, Pyne DB, Guelfi KJ, McCormick RH, Laarakkers CM, et al. Factors influencing the post-exercise hepcidin-25 response in elite athletes. Eur J App/ Physiol. 2017;117:1233-9.

38. Peeling P, Dawson B, Goodman C, Landers G, Trinder D. Athletic induced iron deficiency: new insights into the role of inflammation, cytokines and hormones. Eur J Appl Physiol. 2008;103:381-91.

39. Telford RD, Sly GJ, Hahn AG, Cunningham RB, Bryant C, Smith JA. Footstrike is the major cause of hemolysis during running. J Appl Physiol. 2003;94:38-42.

40. $\operatorname{Sim~M,~Dawson~B,~Landers~G,~Trinder~D,~Peeling~P.~Iron~regulation~in~athletes:~Exploring~}$ the menstrual cycle and effects of different exercise modalities on hepcidin production. Int J Sport Nutr Exerc Metab. 2014;24:177-87.

41. Díaz V, Peinado AB, Barba-Moreno L, Altamura S, Butragueño J, González-Gross M, et al. Elevated hepcidin serum level in response to inflammatory and iron signals in exercising athletes is independent of moderate supplementation with vitamin C and E. Physiol Rep. 2015;3:e12475.

42. Peeling P, Dawson B, Goodman C, Landers G, WiegerinckET, Swinkels DW, et al. Effects of exercise on hepcidin response and iron metabolism during recovery. Int J Sport Nutr Exerc Metab. 2009;1 19:583-97.

43. Newlin MK, Williams S, McNamara T, Tjalsma H, Swinkels DW. The effects of acute exercise bouts on hepcidin in women. Int J Sport Nutr Exerc Metab. 2012;22:79-88.

44. Peeling P, Dawson B, Goodman C, Landers G, Wiegerinck ET, Swinkels DW, et al. Training surface and intensity: inflammation, hemolysis, and hepcidin expression. Med SciSport Exerc. 2009;41:1138-45

45. Peeling P, Dawson B, Goodman C, Landers G, Wiegerinck ET, Swinkels DW, et al. Cumulative effects of consecutive running sessions on hemolysis, inflammation and hepcidin activity. Eur J Appl Physiol. 2009;106:51-9.

46. Sim M, Dawson B, Landers G, Swinkels D, Tjalsma H, Trinder D, et al. Effect of exercise modality and intensity on post-exercise interleukin-6 and hepcidin levels. Int J Sport Nutr Exerc Metab. 2013;23:178-86.

47. Auersperger I, Knap B, Jerin A, Blagus R, Lainscak M, Skitek M, et al. The effects of 8 weeks of endurance running on hepcidin concentrations, inflammatory parameters and iron status in female runners. Int J Sport Nutr Exerc Metab. 2012;22:55-63.

48. DellaValle DM, Haas JD. Impact of iron depletion without anemia on performance in trained endurance athletes at the beginning of a training season: A study of female collegiate rowers. Int J Sport Nutr Exerc Metab. 2011;21:501-6.

49. Harvey LJ, Armah CN, Dainty JR, Foxall RJ, Lewis DJ, Langford NJ, et al. Impact of menstrual blood loss and diet on iron deficiency among women in the UK. Br J Nutr. 2005;94:557-64.

50. Kim I, Yetley EA, Calvo MS. Variations in iron-status during the menstrual cycle. Am Jorunal Clin Nutr. 1993;58:705-9.

51. Lainé F, Angeli A, Ropert M, Jezequel C, Bardou-Jacquet E, Deugnier Y, et al. Variations of hepcidin and iron-status parameters during the menstrual cycle in healthy women. Br J Haematol. 2016;175:980-2.

52. Pottratz S, Bellido T, Mocharla H, Crabb D, Manolagas S. 17- $\beta$ Estradiol inhibits expression of human interleukin- 6 promoter-reporter constructs by a receptor-dependent mechanism. J Clin Invest. 1994;93:944-50.

53. Hou Y, Zhang S, Wang L, Li J, Qu G, He J, et al. Estrogen regulates iron homeostasis through governing hepatic hepcidin expression via an estrogen response element. Gene. 2012;511:398-403.

54. Angstwurm MW, Gärtner R, Ziegler-Heitbrock H. Cyclic plasma IL-6 levels during normal menstrual cycle. Cytokine. 1997;9:370-4.

55. Ikeda Y, Tajima S, Izawa-Ishizawa Y, Kihira Y, Ishizawa K, Tomita S, et al. Estrogen regulates hepcidin expression via GPR30-BMP6-dependent signaling in hepatocytes. PLOS One 2012;7:e40465.

56. Robertson LS, Iwanowicz LR, Marranca JM. Identification of centrarchid hepcidins and evidence that 17beta-estradiol disrupts constitutive expression of hepcidin-1 and inducible expression of hepcidin-2 in largemouth bass (Micropterus salmoides). Fish Shellfish Immunol. 2009;26:898-907.

57. Lehtihet M, Bonde Y, Beckman L, Berinder K, Hoybye C, Rudling M, et al. Circulating hepcidin-25 is reduced by endogenous estrogen in humans. PLoS One. 2016;1 1:e0148802.

58. Yang $Q$, Jian J, Katz S, Abramson SB, Huang X. 17- $\beta$ Estradiol inhibits iron Hormone hepcidin through an estrogen responsive element half-site. Endocrinology. 2012; 153:3170-8.

59. Galesloot TE, Vermeulen SH, Geurts-Moespot AJ, Klaver SM, Kroot JJ, Van Tienoven $D$, et al. Serum hepcidin: reference ranges and biochemical correlates in the general population. Blood. 2011;117:218-26.

60. Li X, Rhee DK, Malhotra R, Mayeur C, Hurst L, Ager E, et al. Progesterone receptor membrane component-1 regulates hepcidin biosynthesis. J Clin Invest. 2016;126:389-401.

61. Konecna L, Yan MS, Miller LE, Schölmerich J, Falk W, Straub RH. Modulation of IL-6 production during the menstrual cycle in vivo and in vitro. Brain Behav Immun. 2000;14: 49-61.

62. Salkeld BD, MacAulay JC, Ball RW, Cannon JG. Modulation of body temperature, interleukin-6 and leptin by oral contraceptive use. Neuroimmunomodulation. 2001;9:319-25.

63. Ives SJ, Blegen M, Coughlin MA, Redmond J, Matthews T, Paolone V. Salivary estradiol, interleukin-6 production, and the relationship to substrate metabolism during exercise in females. Eur J Appl Physiol. 2011;111:1649-58.

64. Sim M, Dawson B, Landers G, Swinkels DW, Tjalsma H, Yeap BB, et al. Oral contraception does not alter typical post-exercise interleukin-6 and hepcidin levels in females. J Sci Med Sport. 2015;18:8-12.

65. Sim M, Dawson B, Landers G, Swinkels DW, Wiegerinck E, Yeap BB, et al. Interleukin-6 and hepcidin levels during hormone-deplete and hormone-replete phases of an oral contraceptive cycle: a pilot study. Ann Nutr Metab. 2017;70:100-5. 